\title{
Acuphagia- A Rare Case of Ingestion of Safety Pins in Young Lady
}

\author{
Authors \\ Dr Govind Madhav (MBBS, DNB)*, Dr Subodh Gupta (MBBS,MS,DNB, FACS, \\ FIAGES, HOD and Senior Consultant), Dr Suman Akula (MBBS, DNB ,FMAS), \\ Dr Sarath Chandran (MBBS, DNB) \\ Department of General Surgery Jaipur Golden Hospital, Sector -3, Rohini, New Delhi, India \\ *Corresponding Author \\ Dr Govind Madhav
}

Abstract
Acuphagia is a rare form of pica, in which a person has compulsive desire to eat metallic sharp objects.
A 20 years lady came with complains of pain abdomen with decreased appetite and loss of weight over last
3 months. Initially she was treated for gastritis but her symptoms persisted. Her upper GI endoscopy was
performed which showed multiple safety pins in stomach with erosion of gastric and duodenal mucosa.
Laparotomy and anterior gastrotomy was performed and around 600 grams of safety pins were removed.
Her post op period was uneventful. Psychiatric evaluation was done and managed accordingly.
Keyword: Acuphagia, Safety pins in stomach, Anterior Gatrotomy.

\section{Introduction}

Pica is defined by the American Psychiatric association as persistent eating of non-nutritional substance, that is inappropriate to developmental level, occurs outside culturally sanctioned practice and if observed during course of another mental disorder, it warrant attention and must have occurred for at least for a month ${ }^{[1]}$.

Term Pica is derived from Latin word Megpie, a bird which have indiscrimination preference food and non-food ${ }^{[2]}$.

In adults, it may be commonly associated with pregnancy or in cases of mental illness.

So in these cases part of successful treatment includes treatment of underlying Psychiatric illness as well ${ }^{[3]}$.

\section{Case Report}

20 years lady came to hospital with complaint of pain in upper abdomen, decreased appetite and loss of weight over last 3 months. She was initially treated for gastritis, but her symptoms persisted. On examination her vitals were stable, had minimal tenderness in epigastric region. Rest other systemic examinations were unremarkable. She visited gastroenterologist and underwent upper GI endoscopy. Endoscopy showed multiple entangled safety pins in the body and fundus region of stomach. Gastric and duodenal mucosa had erosion. She was planned for surgery and underwent laparotomy. Anterior gastrotomy and removal of around 600 grams of safety pins was performed. Post op period was uneventful and she recovered well. Upon discharge she was referred for Psychiatric evaluation and management. 


\section{JMSCR Vol||08||Issue||07||Page 499-502||July}

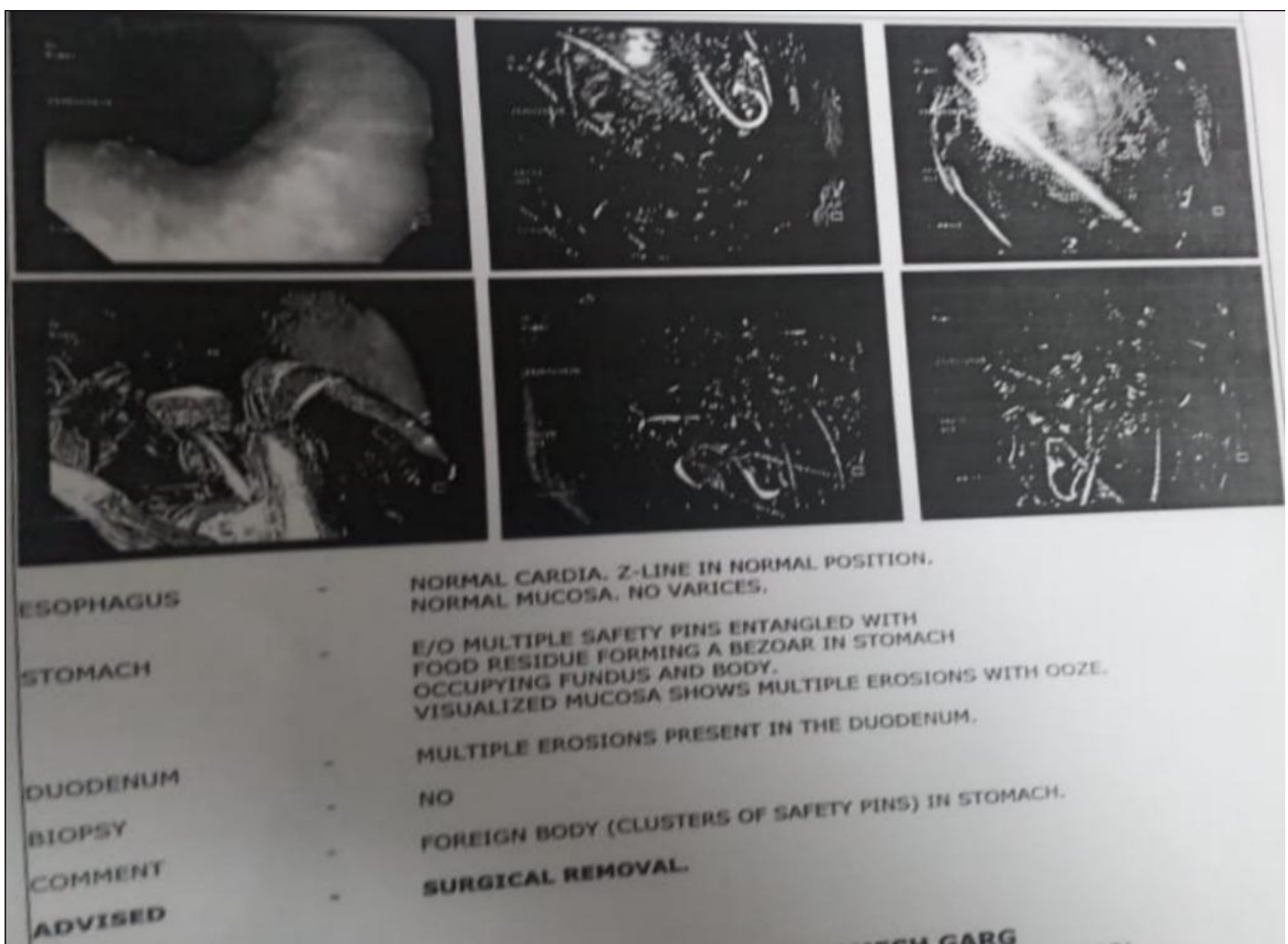

Figure 1- Upper GI endoscopy report

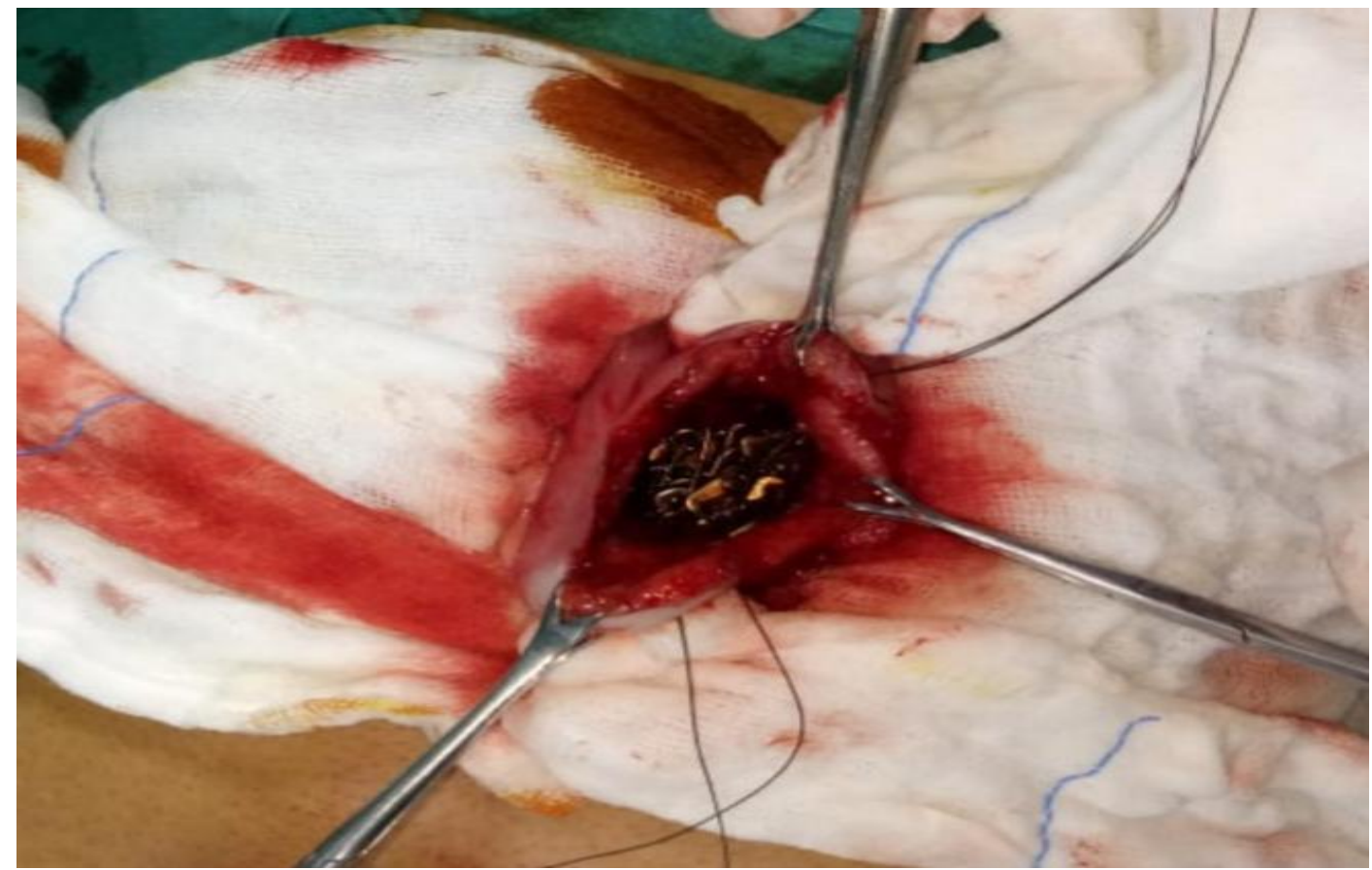

Figure 2-Intra operative - Gastrotomy with safety pins in situ 


\section{JMSCR VoI||08||Issue||07||Page 499-502||July}

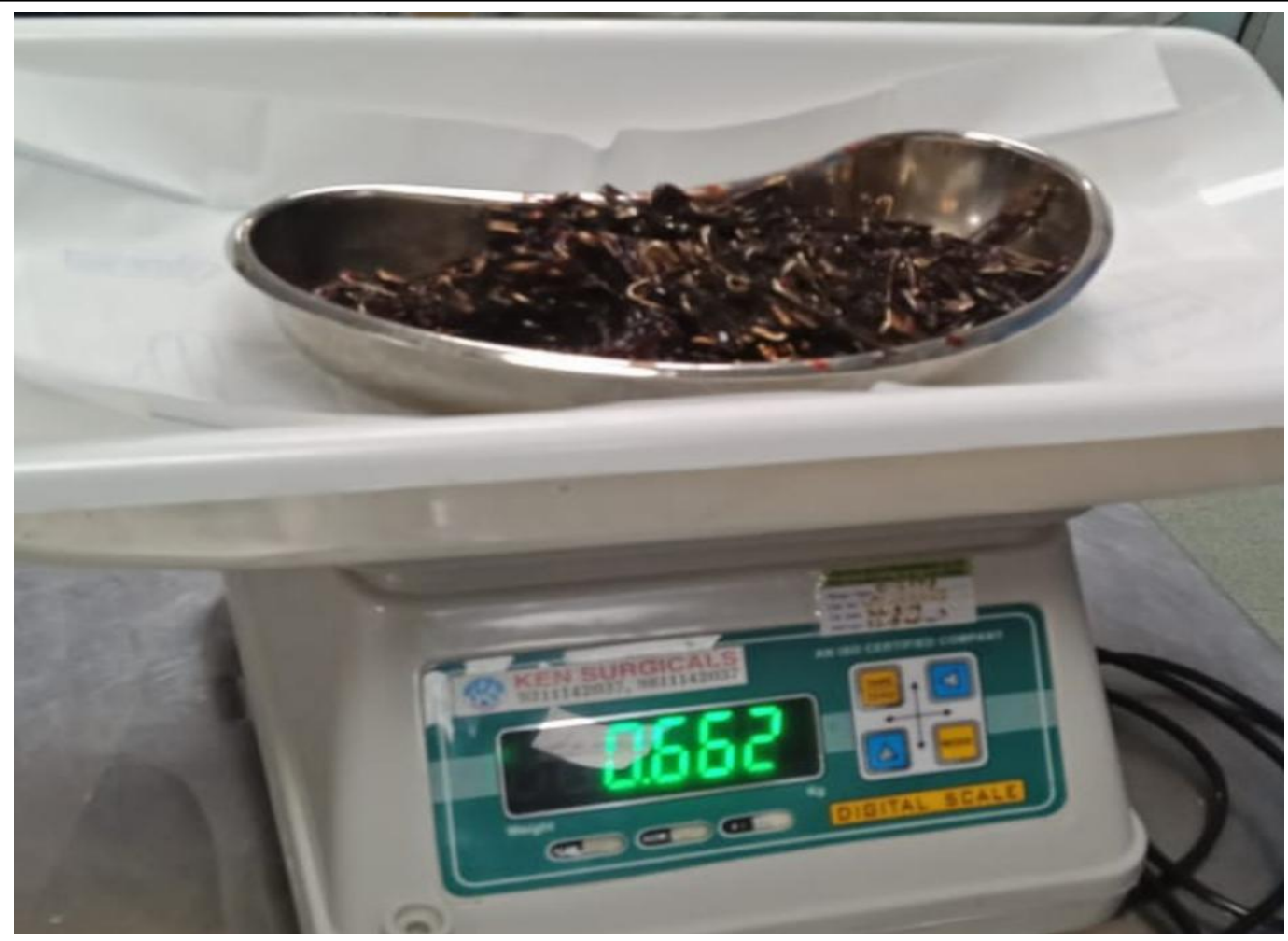

Figure 3- Around 600 grams of safety pins

\section{Discussion}

Most cases of deliberate ingestion of foreign bodies are seen in children with peak incidence between 6 months to 6 years ${ }^{[3]}$.

Acuphagia is a rare form of pica when one has strong urge to ingest metallic object.

Most of the ingested objects passed within 4-6 days after ingestion, some can take even 4 weeks to pass ${ }^{[4]}$. Most of foreign body (around $80 \%$ ) which reach stomach will pass uneventfully through the GI tract, $10-20 \%$ will require non operative intervention and around $1 \%$ or less will require surgery because of obstruction, perforation or hemorrhage ${ }^{[5-6]}$.

Very few of them can even die after ingestion of large amount of metallic foreign bodies ${ }^{[7]}$.

Non pharmacological (cognitive behavioral therapy) and pharmacologic Psychiatric management are important part of treatment of such patients.

This patient has recovered well after surgery and she continues to take treatment from department of Psychiatry for her illness and she is doing well.

\section{Conclusion}

Acuphagia is serious psychiatric condition which can lead to complication of GI tract as obstruction, perforation and hemorrhage in GI tract and sometimes death. These patients need surgical as well as Psychiatric consultation for evaluation, management and prevention of relapses.

\section{References}

1. American Psychiatric Association. Diagnostic and statistical manual of mental disorders (DSM-5®). American Psychiatric Pub; 2013 May 22.

2. Beecroft N, Bach L, Tunstall N, Howard R. Case report: an unusual case of pica. International journal of geriatric psychiatry. 1998 Sep;13(9):638-41.

3. Webb WA. Management of foreign bodies of the upper gastrointestinal tract: update. Gastrointestinal endoscopy. 1995 Jan 1;41(1):39-51.

4. Márquez-Rojas J, Roldán-Baños S, LópezGuerra D, Onieva-González FG, JiménezRedondo JL, Leal-Macho A. Bezoar after 
ingestion of metallic foreign bodies.

Cirugia y cirujanos. 2011;79(5):464-7.

5. Prieto-Aldape MR, Almaguer-García FI, Figueroa-Jiménez SE, Fernández-Díaz $\mathrm{O}$, Mora-Huerta JA, González-Ojeda A. Relapsing massive metal bezoar: a case report. Journal of medical case reports. 2009 Dec;3(1):1-4.

6. Bhatti S, Malik AA, Rafaqat M, Ishaque U, Ayyaz M. Acuphagia as a cause of gastric bezoar causing gastric outlet obstruction. Journal of the College of Physicians and Surgeons Pakistan. 2014 Nov 1;24(Special Supplement 3):190.

7. Emamhadi MA, Najari F, Hedayatshode MJ, Sharif S. Sudden Death Following Oral Intake of Metal Objects (Acuphagia): a Case Report. Emergency. 2018;6(1).

8. Halliday D, Iroegbu F. Case Report 'ACUPHAGIA'-An Adult Nigerian Who Ingested 497 Sharp Metallic Objects. Editorial Advisory Board. 2007;4(2):54. 